OPEN ACCESS

Edited by:

Octavio Luiz Franco,

Universidade Católica de Brasilia,

Brazil

Reviewed by:

Piyush Baindara,

Institute of Microbial Technology

(CSIR), India

Camila Guimarães Freitas,

Federal Institute of Brasilia, Brazil

${ }^{*}$ Correspondence:

Asad U. Khan

asad.k@rediffmail.com

tThese authors have contributed equally to this work.

Specialty section:

This article was submitted to

Antimicrobials, Resistance

and Chemotherapy,

a section of the journal

Frontiers in Microbiology

Received: 25 May 2017 Accepted: 14 August 2017

Published: 29 August 2017

Citation:

Khan SN, Khan S, lqbal J, Khan R and Khan AU (2017) Enhanced Killing and Antibiofilm Activity

of Encapsulated Cinnamaldehyde against Candida albicans.

Front. Microbiol. 8:1641.

doi: 10.3389/fmicb.2017.01641

\section{Enhanced Killing and Antibiofilm Activity of Encapsulated Cinnamaldehyde against Candida albicans}

\author{
Shahper N. Khan', Shakir Khan', Jawed lqbal, Rosina Khan and Asad U. Khan* \\ Interdisciplinary Biotechnology Unit, Aligarh Muslim University, Aligarh, India
}

Candida sp. impelled opportunistic infection in immune-compromised patients ensuing from asymptomatic colonization to pathogenic forms. Moreover, slow spread of Candida species inducing refractory mucosal and invasive infections brings acute resistance to antifungal drugs. Hence, here we probed the effect of encapsulated preparation of cinnamaldehyde (CNMA) in multilamellar liposomes (ML) against Candida albicans. The efficacy of ML-CNMA against Candida biofilm was assessed by scanning electron microscopy, transmission electron microscopy, as well as light microscopy and its percent inhibition, was determined by XTT [2,3-bis-(2-methoxy-4-nitro-5-sulfophenyl)$2 \mathrm{H}$-tetrazolium-5-carboxanilide] and crystal violet assay. ML-CNMA showed more fungicidal activity than free CNMA as well as multilamellar liposomal amphotericin B (ML-Amp B), which was further confirmed by spot test assay and Log-logistic dose-response analysis. Antifungal activity was driven by reactive oxygen species and cellular damage by sustained release of CNMA. Effect on hyphal formation during $48 \mathrm{~h}$ in presence/absence of ML-CNMA was observed under a microscope and further substantiated by RT-PCR by amplifying HWP1, the gene responsible for hyphal wall protein formation. Apoptotic programmed cell death was analyzed by FACS analysis which was further confirmed by cytochrome $C$ release assay. This study elucidates the mechanistic insight of the enhanced antifungal activity of ML preparation of CNMA against Candida infections.

\section{Keywords: CNMA, multilamellar liposome, apoptosis, biofilm, Candida albicans}

\section{INTRODUCTION}

The threat of developing HIV-related complications differs with the extent of immunosuppression in patients (Wadhwa et al., 2007). In spite of the promising effect of antiretroviral therapy on the infectious complications of HIV/AIDS (Michelet et al., 1998), candidiasis stands alone as a major opportunistic infection in HIV-infected cases (Revankar et al., 1998; Morgan, 2005). Candida albicans is a pathogen, causing a multitude of oral and vaginal infections to severe systemic disorders in immune compromised patients (Fidel, 2006; Perlroth et al., 2007). It forms biofilms, an organized and highly structured community of cells (Jin et al., 2005; Ramage et al., 2005), which lately enhanced resistance against antimicrobial agents as well as to host defenses, with profound clinical implications (Costerton et al., 1999; Donlan, 2001; Khan and Khan, 2016). Candida infections are getting resistant to fluconazole and amphotericin B (Amp B; Pfaller, 1996; Mah and O'Toole, 2001). 
It has been reported that on treatment of systemic and topical fungal infections with liposomal (Berenguer et al., 1994) or lipid (Caillot et al., 1993) formulations of antifungal drugs reduces Amp B toxicity and an increase in therapeutic index (Ralph et al., 1991). The earlier studies have revealed the existence of apoptotic cell death responses in yeast (Madeo et al., 1997; Shirtliff et al., 2009; Khan et al., 2012). In fact, various antifungal agents, such as Amp B (Phillips et al., 2003), have already been illustrated to act as yeast-specific apoptotic programmed cell death-inducer. Mitochondria playing the central role in apoptosis, and the inhibition of the mitochondrial electron transport chain, leads to consequent discharge of reactive oxygen species (ROS), as an early event in apoptotic cell death (Westwater et al., 2005; Zhang et al., 2005).

Cinnamaldehyde (CNMA) is a major constituent of Cinnamomum zeylanicum (Lauraceae) extract, which is a widely used flavoring compound that has traditionally been used to treat human diseases, including dyspepsia, gastritis, and inflammatory diseases. Studies have demonstrated that CNMA exhibits antioxidant (Molania et al., 2012), antiinflammatory (Kang et al., 2016), and anticancer activity (Lin et al., 2013), and the compound has been classified as a generally recognized as safe (GRAS) molecule for food preservation by the United States Food and Drug Administration (Wei et al., 2011). CNMA has proven to be effective against some species of toxicogenic fungi and also against respiratory tract pathogens, including Aspergillus, Candida, and Cryptococcus (Shreaz et al., 2016). The restrictive factors for these compounds are their high volatility, sparingly water solubility, and the irritant effect that make difficult to formulate preparations containing them. Therefore, encapsulating CNMA in lipid multilayer could address some of these concerns by preventing their degradation, control release rate, improve bioavailability, lowering dose frequency, and enhanced antimicrobial activities. Hence, we initiated our study to demonstrate the antibiofilm and apoptotic effect of encapsulated multilamellar liposomes (ML)-CNMA on C. albicans.

\section{MATERIALS AND METHODS}

\section{Growth Condition of Microorganism}

Candida albicans ATCC 24433 and clinical isolates (i.e., CA11, CA5, CA3, and CA16 ) were grown in yeast peptone dextrose (YPD) medium; $1 \%$ yeast extract, $2 \%$ peptone, $2 \%$ dextrose (HiMedia) at $37^{\circ} \mathrm{C}$ overnight. Cells were harvested and washed twice with sterile phosphate-buffered saline (PBS; $10 \mathrm{mM}$ phosphate buffer, $2.7 \mathrm{mM}$ potassium chloride, $137 \mathrm{mM}$ sodium chloride; pH 7.4; Jin et al., 2003). Cells were re-suspended in RPMI 1640 supplemented with L-glutamine and buffered with morpholine propane sulfonic acid (MOPS) (HiMedia) and adjusted to the desired density for antibiofilm assay $\left[10^{7}\right.$ cells $\cdot \mathrm{ml}^{-1}$ at 0.1 optical density (OD), absorption at $600 \mathrm{~nm}$ ] and also counted with a hemocytometer (Chandra et al., 2001). The cell density maintained at $0.5-2.5 \times 10^{3} \mathrm{cells}^{\mathrm{m}} \mathrm{ml}^{-1}$ (in RPMI 1640 medium with L-glutamine with MOPS) for the broth microdilution susceptibility assay conferring to CLSI M27-A2 procedure (Park et al., 2006).

\section{Liposomes Preparation}

The "hand shaking" method was used for the preparation of ML-CNMA and ML-Amp B (Trafny et al., 1995). At $37^{\circ} \mathrm{C}$ temperature, $100 \mathrm{mg}$ sample of phosphatidylcholine (SigmaAldrich, India) and $50 \mathrm{mg}$ of cholesterol (Sigma-Aldrich, India) were suspended in $5 \mathrm{ml}$ of chloroform, in the round bottom flask connected with rotary evaporator. The evaporation process continued until dry film visualization. The residual solvent was removed by vacuum evaporation for $1 \mathrm{~h}$, and then $5 \mathrm{ml}$ of Amp B (200-900 mg. $\mathrm{l}^{-1}$; dissolved in $1: 1$ of $1 \%$ DMSO:PBS) and CNMA (0.50-1 mg. $\mathrm{l}^{-1}$; dissolved in 1\% DMSO) were added for the synthesis of ML-Amp B and ML-CNMA, respectively. The rotatory flask was evaporated at $60 \mathrm{rpm}$ for $30 \mathrm{~min}$ at room temperature and then put in the stagnant position for $2 \mathrm{~h}$. The liposomal non-entrapped Amp B and CNMA was separated by overnight dialysis by corresponding 1\% DMSO:PBS and 1\% DMSO solvents, respectively. For the quantification of entrapped drugs, liposomes were ruptured by treatment with $0.1 \%$ sodium deoxycholate and released drugs concentration were calculated by comparison with standard calibration graphs (for released Amp B; calculations based on UV-Vis absorption vs. drug concentrations, see Supplementary Figure S1, and for released CNMA; calculations based on colony forming unit $\left[\mathrm{CFU}=\log _{10}\right.$ (cells. $\mathrm{ml}^{-1}$ ) vs. CNMA concentrations], see Supplementary Figure S2). ML-CNMA and ML-Amp B was used throughout the study. The central values of synthesized liposomes in mean $\pm \mathrm{SD}$ size were measured by Malvern Zetasizer Nano ZS (Malvern, Southborough, MA, United States).

\section{Determination of Minimum Inhibitory Concentration}

Candida albicans were found sensitive to the Amp B/ML-Amp $\mathrm{B}$ and CNMA/ML-CNMA fraction. For minimum inhibitory concentration (MIC), serial dilutions of the CNMA (initial concentration $1 \mathrm{~g} \cdot \mathrm{ml}^{-1}$ ) and Amp B (initial concentration $1 \mathrm{mg} \cdot \mathrm{ml}^{-1}$ ) were performed according to CLSI M27-A2 procedure (Park et al., 2006). The range of liposomes that have different drugs' concentrations (i.e., quantified by calibrated UVVis and CFU. for ML-Amp B and ML-CNMA, respectively) used to identify the liposomal drugs MIC values. Each fungal inoculum was prepared in normal saline and density was adjusted to $0.1 \mathrm{OD} ; 0.5-2.5 \times 10^{3}$ cells $\cdot \mathrm{ml}^{-1}$ (absorption at $600 \mathrm{~nm}$ ). Microtiter plates were incubated incubator (Thermo Fisher Scientific incubator) at $37^{\circ} \mathrm{C}$ and the MIC was recorded after 24-48 h. Proper controls of dissolvent (i.e., solvent of drugs) as blank control, fungal inoculum as positive control and empty lipid carrier as negative control were used throughout the study.

\section{Spot Test for Drug Susceptibility and Drug-Cell Viability Analysis}

Candida albicans ATCC 24433 was further rechecked for their resistance to free and ML-Amp B as well as ML-CNMA by spot test. Strains were grown overnight on YPD plates at $37^{\circ} \mathrm{C}$. Cells 
were then suspended in normal saline to $0.1 \mathrm{OD}$ (absorption at $600 \mathrm{~nm}$ ). A $5 \mu \mathrm{l}$ of fivefold serial dilutions of each yeast culture was spotted onto YPD plates in the absence (control) of any drug and presence of free and ML-Amp B as well as ML-CNMA. Growth differences were recorded after incubation of plates for $48 \mathrm{~h}$ at $37^{\circ} \mathrm{C}$. Growth was not affected by the presence of the controls of dissolvent (i.e., solvent of drugs) as blank control and empty lipid carrier as negative control used for the drugs. The dose-response (drug-cell viability) was used to determine the effective concentrations of the drug $(E)$ for percentage decrease in Candida cell viability (CV). This in vitro method used to predict the exact concentration of drug that may effective for the in vivo model (Hawser and Douglas, 1995; Larsen et al., 2005). The data; \% percentage values of viability corresponding to used drug concentrations were determined by CFU. Nonlinear regression was applied to the data from the dose-response experiments using the statistical freeware program R 3.2.4 with the $d r c$ package (Ritz et al., 2015). A four-parameter equation (Eq. 1) was used to describe the dose-response curves. The effect of ML-CNMA on the $\mathrm{CV}$ was assumed to follow a log-logistic four parameter model (Streibig et al., 1993).

$$
\mathrm{CV}(x)=C+\frac{D-C}{1+\exp \left(b\left(\log (x)-\log \left(E_{\%}\right)\right)\right)}
$$

The CV denotes the viability of $C$. albicans cells as a function of the concentrations of drugs $(x)$. The $D$ and $C$ are the upper and lower asymptotes of $\mathrm{CV}$ at 0 and maximum drugs, respectively. The calculations drugs concentrations (denoted by $E$ ) are corresponding of the reduced CV (\%) (midway between the $D$ and $C$ ). The slope of the curve at $E_{\%}$ is proportional to $b$.

\section{Candida Biofilm Formation}

Biofilms were produced on commercially available pre-sterilized, polystyrene, flat-bottom 96-well microtiter plates (TPC96, HiMedia, India) as reported earlier (Kuhn et al., 2002). As controls, three wells of each microtiter plate were handled in an identical fashion, except that no Candida suspension was added. Following the adhesion phase (i.e., $10^{7}$ cells incubated in $100 \mu \mathrm{l}$ RPMI media for $90 \mathrm{~min}$ at $70-150 \mathrm{rpm}$ at $37^{\circ} \mathrm{C}$ ), the cell suspensions were aspirated and each well was washed twice with $150 \mu \mathrm{l}$ of PBS to remove loosely adherent cells. A total of $100 \mu \mathrm{l}$ of RPMI 1640 was then transferred into each of the washed wells with a pipette, and the plates were incubated at $37^{\circ} \mathrm{C}$ in a shaker at $75 \mathrm{rpm}$. The biofilms were allowed to develop for 24 and $48 \mathrm{~h}$ and then the yeasts were visualized under a microscope and quantified by XTT [2,3-bis-(2-methoxy-4-nitro-5-sulfophenyl)$2 \mathrm{H}$-tetrazolium-5-carboxanilide] and crystal violet assays. All assays were carried out on three different occasions in triplicate with proper controls of dissolvent (i.e., solvent of drugs) as blank control, fungal inoculum as positive control and empty lipid carrier as negative control were used throughout the study (Jin et al., 2003).

\section{Crystal Violet Staining}

Candida albicans biofilm was assessed by microdilution method and quantified by a slight modification of a crystal violet assay as described earlier (Jin et al., 2003). A six different concentrations $\left(550,500,450,400,350,300 \mathrm{mg} \cdot \mathrm{l}^{-1}\right)$ of CNMA as well as six different concentrations $\left(300,240,155,80,56,30 \mathrm{mg} \cdot \mathrm{l}^{-1}\right)$ of CNMA (@/in ML) were used to treat the Candida biofilm. And also, a five different concentrations of Amp B (0.45, 0.40, 0.35, 0.30 , and $\left.0.25 \mathrm{mg} \cdot \mathrm{l}^{-1}\right)$ as well as five different concentrations of Amp B $\left(0.60,0.55,0.50,0.45\right.$, and $\left.0.40 \mathrm{mg} \cdot \mathrm{l}^{-1}\right) @ /$ in were used to treat the Candida biofilm. The biofilm developed in microtiter plates were twice washed with $200 \mu \mathrm{l}$ PBS and then air dried for $45 \mathrm{~min}$. The wells were stained with $110 \mu \mathrm{l}$ of $0.4 \%$ aqueous crystal violet (Sigma-Aldrich, India) solution for $45 \mathrm{~min}$. Afterward, washing was done four times with $350 \mu \mathrm{l}$ of sterile distilled water and subsequently destained with $200 \mu \mathrm{l}$ of $95 \%$ ethanol. After $45 \mathrm{~min}$ of destaining, $100 \mu \mathrm{l}$ of the destaining solution was transferred to a new well and the amount of the crystal violet stain in the destaining solution was measured with a microtiter plate reader (Bio-Rad Laboratories) at $595 \mathrm{~nm}$. The absorbance values for the controls were subtracted from the values for the test wells to minimize background interference. The percentage of biofilm reduction was calculated by the following equation.

$$
\text { Biofilm reduction }(\%)=\left(1-\frac{\mathrm{OD}_{\text {treated }} @ 595 \mathrm{~nm}}{\mathrm{OD}_{\text {control }} @ 595 \mathrm{~nm}}\right) \times 100 \%
$$

\section{XTT Assay}

This assay was performed by previously described methods (Jin et al., 2003; Kuhn et al., 2003). A 1 mg.l ${ }^{-1}$ XTT (Sigma, MO, United States) solution was prepared in PBS. The XTT was filtered and sterilized using a $0.22 \mu \mathrm{m}$-pore-size filter and then stored at $-70^{\circ} \mathrm{C}$ until required. Menadione (Sigma, MO, United States) solution $(0.4 \mathrm{mM})$ was also prepared and filtered immediately before each assay. Prior to each assay, XTT solution was thawed and mixed with menadione solution at a volume ratio of 20:1. The adherent cells were washed four times with $200 \mu \mathrm{l}$ of PBS to remove loosely adherent cells. Afterward, $158 \mu \mathrm{l}$ of PBS, $40 \mu \mathrm{l}$ of XTT, and $2 \mu \mathrm{l}$ of menadione were inoculated to each of the prewashed wells. After incubation in the dark for $2 \mathrm{~h}$ at $37^{\circ} \mathrm{C}, 100 \mu \mathrm{l}$ of the solution was transferred to a new well and a colorimetric change in the solution was measured using a microtiter plate reader (Bio-Rad Laboratories) at $490 \mathrm{~nm}$.

\section{Microscopic Study}

Treated and control Biofilms were scraped, re-suspended in sterilized distilled water containing one drop of $50 \mathrm{mg} \cdot \mathrm{l}^{-1}$ propidium iodide (PI; Sigma) as well as one drop of $0.0025 \%$ Fluorescent Brightener 28 (Sigma Chemical, St. Louis, MO, United States) incubated for $10 \mathrm{~min}$ at room temperature in dark (Harrington and Williams, 2007). The fluorescents probed biofilm/cells was washed with distilled water three times. The samples were examined under the light microscope equipped with differential interference contrast (Nomarski) and fluorescence capabilities (IX-81, Olympus). For SEM analysis, C. albicans cells were grown on poly-L-lysine (Sigma) coated glass coverslip discs (HiMedia, India) in 12-well cell culture plates (CoStar, Bethesda, MD, United States). The glass cover slips 
coating with poly-L-lysine ( $2 \% \mathrm{wt} / \mathrm{vol})$ were done according to described method by Dong et al. (2011). This adherent coatings were sterilized for $1 \mathrm{~h}$. in laminar air flow equipped with UV radiation. According to SEM sample protocol (Chandra et al., 2008), here, standardized cell culture ( $2 \mathrm{ml}$ of a suspension containing $10^{7}$ cells $\cdot \mathrm{ml}^{-1}$ in RPMI-1640) were used in each culture plate well and adhered to glass cover slip for $2 \mathrm{~h}$. Cells were treated with ML-CNMA (80, 240, and $300 \mathrm{mg} \cdot \mathrm{l}^{-1}$ ) and incubated at $37^{\circ} \mathrm{C}$. Each disc was removed from culture plate and wash with sterilized PBS. Samples were then dried in a desiccator after treatment of serial ethanol dehydration (at 25, $50,65,95$, and $100 \%$ ethanol; for $15 \mathrm{~min}$ difference in each steps). The samples were sputter coated with gold by cathodic spraying and observed by scanning electron microscope (LEO $435 \mathrm{VP}$ ) at 15KX and $20 \mathrm{KX}$ magnification (Bandara et al., 2010). For TEM, culture material processed according to Bozzola and Russell (1999). Ultra-thin sections of the cells were stained with uranyl acetate and lead citrate and observed under Morgagni 268 (D) transmission electron microscope at $50 \mathrm{KX}$ magnification.

\section{Confocal Laser Scanning Microscopy}

The effects of ML-CNMA on Candida cells during the biofilm formation were analyzed by confocal laser scanning microscopy (CLSM; Chandra et al., 2008). Candida cells were treated with ML-CNMA and incubated at $37^{\circ} \mathrm{C}$ for $12 \mathrm{~h}$ on glass coverslips. After that, these cover slips were removed and transferred to new six-well culture plates and incubated for $45 \mathrm{~min}$ at $37^{\circ} \mathrm{C}$ in $4 \mathrm{ml}$ of $\mathrm{PBS}$ containing the following fluorescent dyes as molecular fluorescent probes. These fluorescent probes are concanavalin A (Con A) Alexa Fluor 488 conjugated, $25 \mu \mathrm{g} \cdot \mathrm{ml}^{-1}$; Invitrogen, Carlsbad, CA, United States), FUN-1 (Fungolight $10 \mu \mathrm{M}$; Invitrogen), and 4,6-diamidino-2-phenylindole (DAPI, $2.5 \mu \mathrm{g} \cdot \mathrm{ml}^{-1}$, Sigma-Aldrich). After incubation with probes, coverslips flipped on glass plates and observed with a FluoView FV1000 (Olympus, Tokyo, Japan) confocal laser scanning microscope equipped with argon and HeNe lasers.

\section{Rate of ROS Generation}

ML-CNMA/CNMA induced ROS generation rate was quantified by an indirect method, where produced ROS oxidized the cytoplasmic dichlorofluorescein diacetate (DCFH-DA) to fluorescent dichlorofluorescein (DCF). Initially, Candida cells treated with ML-CNMA/CNMA for $60 \mathrm{~min}$. Subsequently, a $10 \mathrm{mM}$ DCFH-DA was added and incubated for 10, 15, 30, and $60 \mathrm{~min}$ in $2 \mathrm{ml}$ well microtiter plate at $37^{\circ} \mathrm{C}$. The produced cytoplasmic DCF fluorescence was measured (at $\lambda_{\mathrm{em}}=522 \mathrm{~nm}$ ) following excitation with $\lambda_{\mathrm{ex}}=490 \mathrm{~nm}$ light. The quantity of ROS production was proportional to the amount of fluorescence intensity produced by DCF (emission $=520 \mathrm{~nm}$ ) from the cells. Fluorescent intensity of fluorescent probe was measured by Hitachi (Tokyo, Japan) F-4500X fluorescence spectrometer.

The cytoplasmic DCF fluorescence formation can be expressed as Eq. 3 (Daghastanli et al., 2008). Here, $F_{(t)}$ is the intensity of fluorescence at time $t, F_{0}$ is the fluorescence at time $0, b$ is a fit parameter, and $k$ is the time constant.

$$
F_{(t)}=F_{0}\left(1-\beta \mathrm{e}^{-t / k}\right)
$$

Hence, the rate of DCF formation $r_{(t)}$ can be measured from $\mathrm{d}\left(F_{t}\right) / \mathrm{dt}$ (Eq. 4).

$$
\mathrm{r}(\mathrm{t})=\frac{\mathrm{d}\left(F_{t}\right)}{\mathrm{dt}}=\frac{\mathrm{d}}{\mathrm{dt}}\left[F_{0}-F_{0} \beta \mathrm{e}^{-t / k}\right]
$$

\section{Apoptosis by FACS Analysis}

PI (Sigma-Aldrich) and annexin V-FITC (Sigma-Aldrich) probes were used to assess the cellular integrity and externalization of phosphatidylserine (PS), respectively. Here, PS is an early marker of apoptosis and probed by annexin V-FITC when it exposed on the plasma membrane's outer surface. Initially, C. albicans cells were protoplasted, where cells $\left(10^{7}\right.$ cells $\left.\cdot \mathrm{ml}^{-1}\right)$ was washed twice in PBS and incubated at $30^{\circ} \mathrm{C}$ for $30 \mathrm{~min}$ in presence of $0.5 \mathrm{ml}$ $(\mathrm{pH} 7.2)$ of $50 \mathrm{mM} \mathrm{K}_{2} \mathrm{HPO}_{4}+5 \mathrm{mM} \mathrm{EDTA}+50 \mathrm{mM}$ DTT. The incubated cells digested by $0.5 \mathrm{ml}(\mathrm{pH} 7.2)$ of $50 \mathrm{mM} \mathrm{KH}{ }_{2} \mathrm{PO}_{4}+40 \mathrm{mM}$ 2-mercaptoethanol $+3 \mu \mathrm{g} \cdot \mathrm{ml}^{-1}$ chitinase (Sigma-Aldrich) $+1.8 \mu \mathrm{g} \cdot \mathrm{ml}^{-1}$ lyticase $+12 \mu \mathrm{l}$ glucuronidase $+0.15 \mathrm{mg} \cdot \mathrm{ml}^{-1}$ zymolyase $+20 \mu \mathrm{l}$ of glusulase in 2.4 M sorbitol. This digestion process takes place for $45 \mathrm{~min}$ at $30^{\circ} \mathrm{C}$. Protoplasts $\left(10^{7}\right.$ cells $\left.\cdot \mathrm{ml}^{-1}\right)$ were washed in modified annexin binding buffer (10 mM HEPES/NaOH, pH 7.4; $40 \mathrm{mM}$ $\mathrm{NaCl}+50 \mathrm{mM} \mathrm{CaCl} 2+1.2 \mathrm{M}$ sorbitol). The protoplasted cells were used for treatment with ML-CNMA (80, 155, and $240 \mu \mathrm{g} \cdot \mathrm{ml}^{-1}$ ) in RPMI 1640 media supplemented with MOPS ( $\mathrm{pH} 7.4$ ) in the culture flask. After $4 \mathrm{~h}$ incubation at $30^{\circ} \mathrm{C}$ with shaking $(75 \mathrm{rpm}$.), cells were harvested and assessed for apoptosis. Annexin-V binding assays were performed according to the protocol of Madeo et al. (1999), in modified annexin binding buffer containing $20 \mu \mathrm{l} \cdot \mathrm{ml}^{-1}$ annexin reagent and $5 \mathrm{mg} \cdot \mathrm{l}^{-1} \mathrm{PI}$. The annexin and PI status of protoplasts were recorded for each treatment, and each assay was repeated in triplicate.

\section{Cytochrome C Assay}

The extent of apoptosis was indirectly quantified by relative concentrations of cytochrome $\mathrm{C}$ (Cyt C) produced in the treated cells' cytoplasm/mitochondria. Here, mitochondria were isolated by the method of Wu et al. (2010). Candida cells were grown in YPD broth at $37^{\circ} \mathrm{C}$ to early stationary phase and quantified by dilution up to $1 \times 10^{7}$ cells. $\mathrm{ml}^{-1}$ with normal saline and further incubated with ML-CNMA (240 mg. $\mathrm{l}^{-1}$ ) at $30^{\circ} \mathrm{C}$ for $24 \mathrm{~h}$. The cells were washed in PBS $(7.2 \mathrm{pH})$ as well as centrifuged at $5000 \times g$ for $5 \mathrm{~min}$. The pellet decanted in the homogenization medium $[50 \mathrm{mM}$ Tris $(\mathrm{pH}$ 7.5), $2 \mathrm{mM}$ EDTA, and $1 \mathrm{mM}$ phenylmethylsulfonyl fluoride], and supplemented with $2 \%$ glucose. Initially, cell debris and unbroken cells were removed from the homogenization medium by $2000 \times g$ centrifugation for $10 \mathrm{~min}$ and, further supernatants were collected after centrifugation at $30,000 \times g$ for $45 \mathrm{~min}$. This supernatants were used for Cyt $\mathrm{C}$ quantification (i.e., released from mitochondria to cytoplasm). The pellet was resuspended in $50 \mathrm{mM}$ Tris $(\mathrm{pH} \mathrm{5.0)}+2 \mathrm{mM}$ EDTA and incubated for $5 \mathrm{~min}$ at $37^{\circ} \mathrm{C}$, and centrifuged at $5000 \times g$ for $30 \mathrm{~s}$. This pellet was used for the determination of Cyt $\mathrm{C}$ remaining in mitochondria. Protein estimations (of supernatant as well as 
pallets) were done according to the method of Bradford (1976), using BSA as the standard. The supernatant and pallets being reduced by $500 \mathrm{mg} \cdot \mathrm{l}^{-1}$ ascorbic acid at room temperature for $5 \mathrm{~min}$ and the amount of $\mathrm{Cyt} \mathrm{C}$ in supernatants and mitochondria were determined by measuring absorbance at $550 \mathrm{~nm}$ with a Spectrofluorophotometer (Shimadzu UV-1700).

\section{RNA Extraction from CNMA/ML-CNMA Treated Candida Cells and RT-PCR}

The Candida cells (ATCC 24433) were treated with CNMA as well as ML-CNMA. The cells (that include positive control/treated and negative control/non-treated) were pelleted and RNA was extracted by using RNA extraction kit (YeaStar RNA Kit, Zymo Research). Pure RNA was quantified and used to synthesize first strand cDNA as manufacturer's instruction (cDNA synthesis kit, Fermentas, United States). PCR reactions were performed by using the primers HWP1 F $5^{\prime}$-CCA CTA CTA CTG AAG CCA AAT C-3'; HWP1 R 5'-AAG TGG ATA CTG TAC CAG TTG G-3'; EFB1 F 5'-AGT CAT TGA ACG AAT TCT TGG CTG- $3^{\prime}$ and EFB1 R $5^{\prime}$-TTC TTC AAC AGC AGC TTG TAA GTC- $3^{\prime}$. The following conditions were used for amplification of $H W P 1: 94^{\circ} \mathrm{C}$ for $5 \mathrm{~min}, 94^{\circ} \mathrm{C}$ for $30 \mathrm{~s}, 56^{\circ} \mathrm{C}$ for $30 \mathrm{~s}, 72^{\circ} \mathrm{C}$ for $30 \mathrm{~s}$, and $72^{\circ} \mathrm{C}$ for $30 \mathrm{~s}$ for 30 cycles and for housekeeping gene; primer $E F B 1$ : $94^{\circ} \mathrm{C}$ for $30 \mathrm{~s}, 60^{\circ} \mathrm{C}$ for $30 \mathrm{~s}$, and $72^{\circ} \mathrm{C}$ for $60 \mathrm{~s}$ (21 cycles), respectively (Davis-Hanna et al., 2008).

\section{Modeling and Docking Simulation}

The amino acid sequence of $14-\alpha$ demethylase for C. albicans was extracted from Swissprot database. As the crystal structure of 14- $\alpha$ demethylase of $C$. albicans was not available within Protein databank, so its 3D model was generated. Blastp search against PDB was performed to search for a suitable template. Crystal structure of human lanosterol 14 $\alpha$-demethylase (CYP51) (PDB id: 3LD6) having $40 \%$ identity with the target was taken as a template for constructing the 3D protein model. Modeler 9v8 was used for building the $3 \mathrm{D}$ structure of $14-\alpha$ demethylase. The coordinates of HEM group were transferred from the template to the generated structure. The model generated was further refined to remove the bad steric clashes by using CharmM force field. Furthermore, the refined structure was validated through Procheck. AmpB and CNMA were docked into the active site of 14- $\alpha$ demethylase using LigandFit docking program (Venkatachalam et al., 2003; Khan et al., 2008).

\section{Statistical Analysis}

The significance and central values of effects (after the treatment of ML-CNMA/Amp B) were analyzed by open source statistical software $\mathrm{R}$ (Comprehensive $\mathrm{R}$ Archive Network; CRAN) (R Development Core Team, 2013). Differences between mean values were assessed either by Student's $t$-test or by one-way analysis of variance (ANOVA), followed by a Newman-Keuls post hoc test. Values of $P<0.05$ and $P<0.001$ were considered to be significant. Bar graphs and other plots were prepared by ggplot2 in R. Graph analysis were done by packages ("ggplot2") downloaded in R console.

\section{RESULTS}

\section{Susceptibility Test}

The effective concentrations of liposome entrapped Amp B and CNMA were calculated by the calibration graphs, where released drugs concentrations compared with UV-Vis absorptions and CFU values, respectively (see Supplementary Figures S3, S4). The MIC values of Amp B and CNMA alone against C. albicans ATCC 24433 are 0.50 and $550 \mathrm{mg} \cdot \mathrm{l}^{-1}$, respectively. Whereas, MICs of ML-Amp B and ML-CNMA are 0.55 and $240 \mathrm{mg} \cdot \mathrm{l}^{-1}$, respectively. Hence, Candida strain ATCC 24433 is merely equal sensitive to the free Amp-B compared to the ML-Amp $B$ whereas, ML-CNMA departed more sensitivity than free CNMA. Further the spot test assay also corroborates enhance fungicidal effects of ML-CNMA as compared to CNMA alone (Figure 1A). To further understand the role of the liposome in $\mathrm{CV}$ of C. albicans, we fitted a dose-response curve to ascertain the cellular viability (Figures 1B,C). Interestingly, our findings showed the necessary concentrations of CNMA (in ML-CNMA formulation) to reduce the 5, 10,50, and $99 \% \mathrm{CV}$ is lower ( 28.6 , 34,56 , and $\left.162 \mathrm{mg} \cdot \mathrm{l}^{-1}\right)$ as compared CNMA alone $(\sim 235,257$, 333, and $\left.572 \mathrm{mg} \cdot \mathrm{l}^{-1}\right)$. The same trends also departed by MLCNMA against clinical isolates (see Supplementary Table S1). Contrary, the same liposome formulation for Amp B showed the opposite result, where the necessary concentrations of Amp $\mathrm{B}$ to reduce the $5,10,50$, and $99 \% \mathrm{CV}$ is about $(\sim 0.060$, $0.074,0.141$, and $\left.0.532 \mathrm{mg} \cdot \mathrm{l}^{-1}\right)$ almost same as compared to Amp B alone $\left(\sim 0.058,0.074,0.147\right.$, and $\left.0.621 \mathrm{mg} \cdot \mathrm{l}^{-1}\right)$. The comprehensive susceptibilities/resistant of clinical isolates were enlisted in the tabular form (Figure 1D), where MIC break point of Amp B taken according to CLSI 2008 guideline (Clinical and Laboratory Standards Institute, 2008) and CNMA break point was $\geq 550 \mathrm{mg} \cdot \mathrm{l}^{-1}$ (MIC against C. albicans ATCC 24433).

\section{Mode of Action of ML-CNMA}

The adhered cells were treated with ML-CNMA (i.e., $300 \mathrm{mg} \cdot \mathrm{l}^{-1}$ CNMA entrapped ML-CNMA) for $24 \mathrm{~h}$ and were investigated under light and scanning electron microscope (Figures 2A,B). Prior to that, the size distribution of the synthesized MLCNMA was $2.7 \pm 3 \mu \mathrm{m}$ size (measured by Malvern Zetasizer Nano ZS; see Supplementary Figure S3). In addition, the light microscope also showed the synthesized ML-CNMA with average size $\sim 3 \mu \mathrm{m}$ (see Supplementary Figure S4). Here, the micrographs show the interaction among the liposomes (Figures 2Aa,b) as well as between liposome and Candida cells (Figures 2Ac,d). Interestingly, after the treatment of biofilm, the size of liposomes increases from $\sim 6.8$ to $\sim 15.2 \mu \mathrm{m}$ during the gap of 2-8 h time period (Supplementary Figure S5). Moreover, SEM images showed a very unambiguous affinity of binding between liposome-liposome and liposome-Candida cells. A sort of groove was observed on contact of cells with liposome (Figures 2Ba,e) through which cells entered into the liposome (Figures $\mathbf{2 B b}, \mathbf{f}$ ) and came in further contact with drug and eventually liposome got ruptured after interaction with large number of Candida cells (Figures 2Bd,g). Further, its antifungal effect on Candida biofilm was observed by treatment with varying 

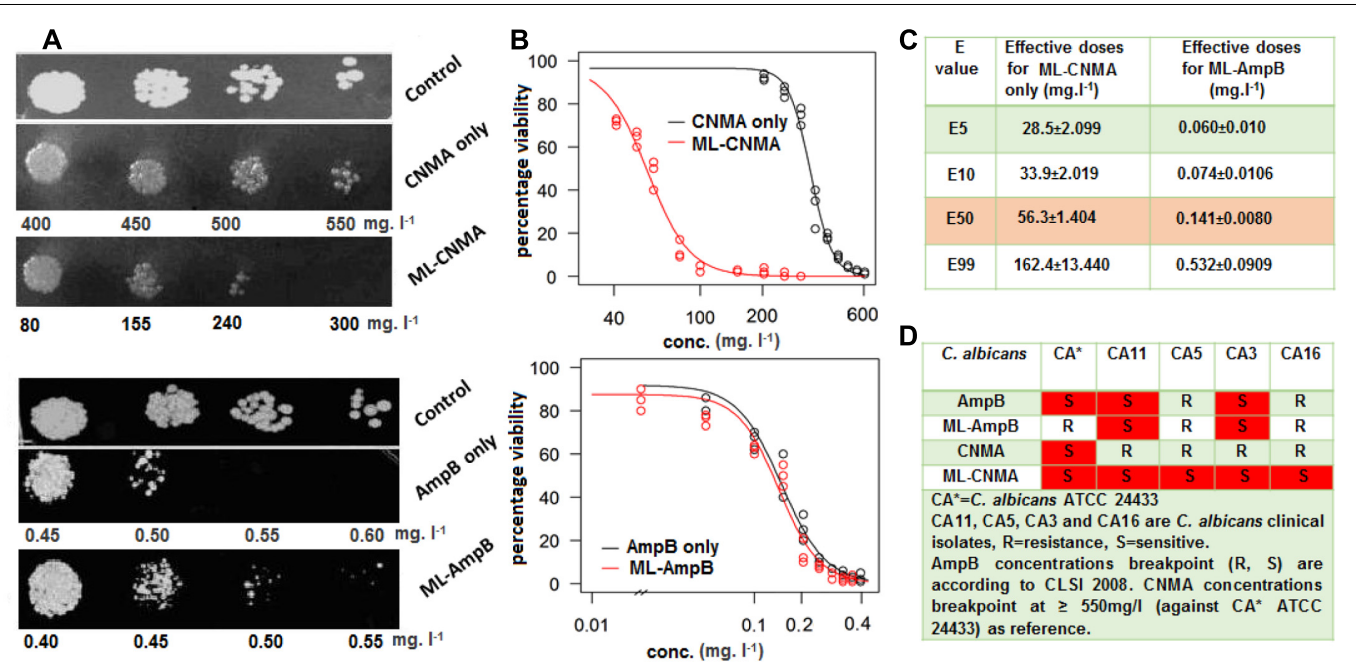

FIGURE 1 | (A) Drug resistance profiles of Candida albicans ATCC 24433 determined by the spot assay. Growth was not affected by the presence of the solvents used for the drugs. (B) Log-logistic dose-response curve illustrating the growth inhibitory effect of both cinnamaldehyde and AmpB in presence and absence of ML. (C) The corresponding table shows the effective dose or concentration of drug (ML-entrapped) for particular percentage inhibition ( $\left.E_{\%}\right)$ in cell viability (data derived by log-logistic dose-response curve analysis). Dissolvent and empty lipid carrier was used as controls. (D) Table shows Susceptibility and resistant profile of drugs/ML-entrapped drugs against various clinical isolates.

concentrations of ML-CNMA (0, 30, 80, and $\left.300 \mathrm{mg} \mathrm{l}^{-1}\right)$ for $24 \mathrm{~h}$. SEM analysis showed the effects of ML-CNMA (Figures $\mathbf{2} \mathbf{C b}-\mathbf{d}$ ) on $C$. albicans biofilm formation. The images (Figures 2Cc,d) showed remarkable biofilm reduction in the presence of ML-CNMA.

\section{Biofilm Reduction}

Further, antibiofilm activity of ML-Amp B and ML-CNMA was observed using crystal violet and XTT reduction assay. Our study revealed that in crystal violet assay, maximum percent inhibition of biofilm formation observed during 24 and $48 \mathrm{~h}$ treatment was $\sim 81$ and $\sim 83 \%$ by ML-CNMA (300 mg. $\mathrm{l}^{-1}$ ), respectively (Figure 3A). Whereas, $\sim 28$ and $\sim 45 \%$ inhibition was found in the presence of ML-Amp B $\left(0.45 \mathrm{mg} \cdot \mathrm{l}^{-1}\right)$ at 24 and $48 \mathrm{~h}$ treatment, respectively (Supplementary Figure S6). We have also employed tetrazolium salt (XTT) reduction assay for quantitative measurement of Candida biofilm formation, as it is more sensitive techniques to study the antifungal activity. Our data showed maximum percent inhibition as $\sim 55$ and $\sim 68 \%$ with the highest time-dependent response at $300 \mathrm{mg} \cdot \mathrm{l}^{-1}$ of ML-CNMA on 24 and $48 \mathrm{~h}$ treatment, respectively (Figure 3B). Whereas, $\sim 35$ and $\sim 62 \%$ inhibition was observed Amp B $\left(0.45 \mathrm{mg} \cdot \mathrm{l}^{-1}\right)$ treatment at 24 and 48 h treatment, respectively (Supplementary Figure S6). Furthermore, comprehensive crystal violet and XTT biofilm reduction assay findings of ML-CNMA against clinical isolates were enlisted in the tabular form (Supplementary Table S2). The ML-CNMA departed the same effect against the clinical isolates as reference C. albicans ATCC 24433 biofilm.

\section{Cyto-Metabolic Effects of ML-CNMA on C. albicans}

TEM has been used to reveal definitive ultra-structural features of the chromatin in apoptotic multicellular organisms. Control cells showed normal cellular morphology with a distinct cell wall and an intact nucleus (Figure 4A). In contrast, cells exposed to ML-CNMA (240 and $300 \mathrm{mg} \cdot \mathrm{l}^{-1}$ ) manifested extensive chromatin condensation as aggregates in the nuclear envelope and tiny vesicles on the outer surface of the plasma membrane, which are the typical marker of apoptosis (Figures 4B,C). Candida cells when observed by SEM in the presence of ML-CNMA (300 mg. $\mathrm{l}^{-1}$ ) for $36 \mathrm{~h}$, showed evident surface blebbing (white arrow), a sign of cell death (Figure 4E) as compared to normal cells (Figure 4D). Further, CLSM was performed to assess cellular metabolic activity, viability, and cell wall integrity using FUN1, Con A, and DAPI fluorescent probes, respectively. FUN1 gets transformed from yellow to the orange-red fluorescent intravacuolar structure by active or viable cells while Con A gives green fluorescence on binding with glucose and mannose moieties of the cell wall and DAPI provides blue fluorescence on intercalation with AT-rich regions of DNA. The untreated/control samples (Figures 4F, $\mathbf{F}^{\prime}$ ) show intact cell wall of green color due to Con A binding along with intra-vacuolar structure in focused orange-red fluorescence and blue color condensed nucleus for FUN1 and DAPI probes, respectively. Whereas, samples of Candida cells treated with 80 and $240 \mathrm{mg} \cdot \mathrm{l}^{-1}$ ML-CNMA (Figures 4G,H), showed cytosolic diffused yellow and orange fluorescence, confirming vacuolar disintegration and fragmentation accompanied by the loss of cell wall integrity as depicted by fading green Con A fluor in metabolic cells. Likewise, DAPI stained treated samples also showed nuclear fragmentation as sprinkled and scattered blue fluor signals along with cell wall degeneration (Figures $\mathbf{4 G}^{\prime}, \mathbf{H}^{\prime}$ ). The nonfluorescent DCFH-DA $\quad\left(2^{\prime}, 7^{\prime}\right.$-dichlorodihydrofluorescein $)$ compound easily penetrates the cell membrane and converts to $2^{\prime}, 7^{\prime}$-DCF, a strong fluorescent molecule by ROS-mediated 
A

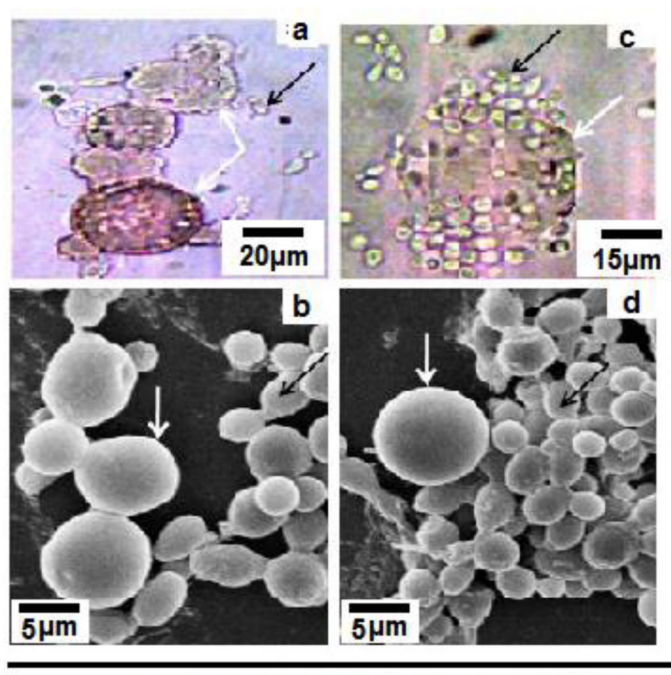

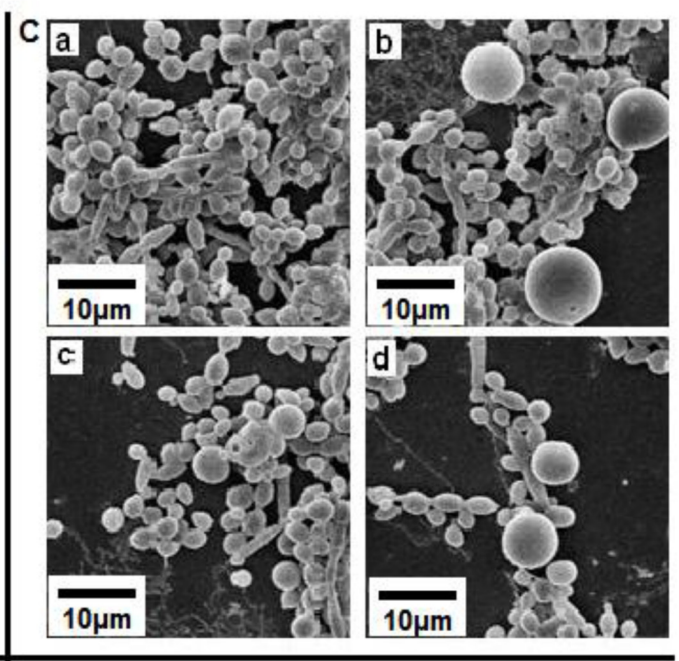

B
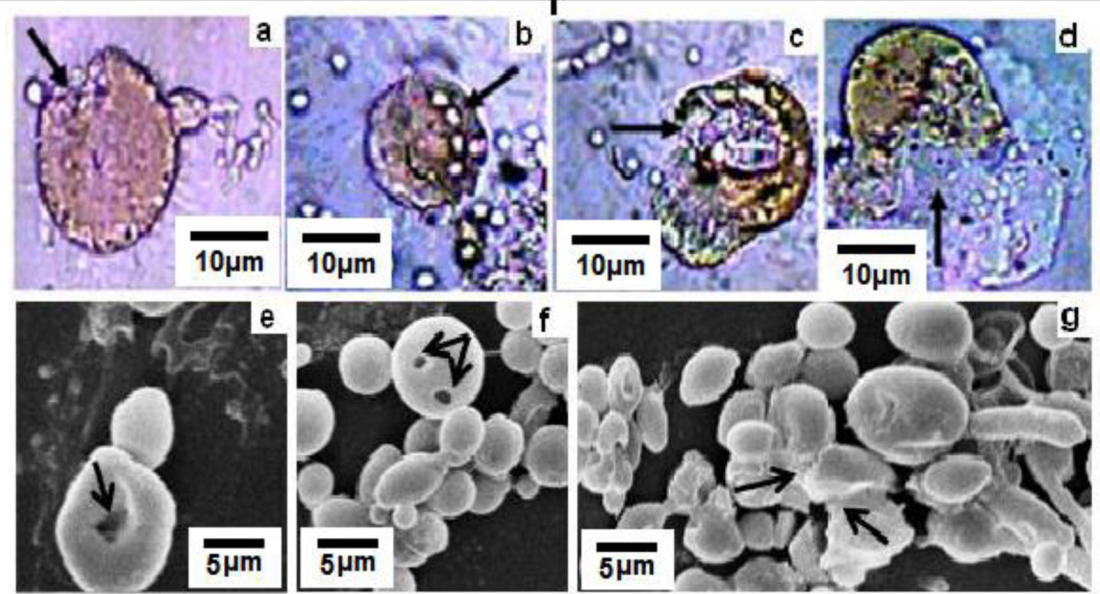

FIGURE 2 | (A) Light (a,c) and scanning electron microscopic (b,d) studies of Candida albicans and ML-CNMA (300 mg.| ${ }^{-1}$ CNMA entrapped ML-CNMA) interaction. Panels (a,b) showed interaction among liposomes, whereas panels (c,d) showed the interaction between the liposome and Candida cells. White arrows indicate liposome whereas black arrows indicate Candida cells. (B) Panels (a,e) showed channels/grooves formed in liposome after attachment of cells, and later elongated Candida cells attached liposome (b,f) formed more grooves. Finally, liposome ruptured $\mathbf{( c , d , g ) ~ c a u s i n g ~ r e l e a s e ~ o f ~ C N M A , ~ i n d i c a t e d ~ b y ~ d i f f e r e n t ~ b l a c k ~}$ arrows. (C) Control biofilm (a) were treated with ML-CNMA (b-d) with increasing concentration $\left(30,80\right.$, and 300 mg. $\left.l^{-1}\right)$ for 24 h at $37^{\circ} \mathrm{C}$. Dissolvent and empty lipid carrier was used as controls.

oxidation (Soh, 2006; Daghastanli et al., 2008; Figure 4I). The enhanced DCF fluorescence $(F)$ is tantamount to ROS formation, hence the rate of fluorescence $\left(F \times 10^{-3} \cdot S^{-1}\right)$ by ML-CNMA treatments are $\sim 2.5$ times higher (for CNMA concentration 240 and $300 \mathrm{mg} \cdot \mathrm{l}^{-1}$ ) as compared to CNMA alone (Figure 4J).

\section{Apoptotic Potential of ML-CNMA on C. albicans}

Cells were labeled with annexin $\mathrm{V}$ and PI to analyze the apoptotic potential of the ML-CNMA formulation. The early and late apoptosis in presence of ML-CNMA (80, 155, and $240 \mu \mathrm{g} \cdot \mathrm{ml}^{-1}$ ) were recorded as $35.1,41.1,48.2 \%$ and 8.9, $9.4,12.2 \%$, respectively (Figure 5A). Whereas in the presence of free CNMA (155 and $240 \mathrm{mg} \cdot \mathrm{l}^{-1}$ ) it was recorded as $30.4,24.8 \%$ and $29.95,30.63 \%$, respectively (data not shown). Necrosis in the presence of ML-CNMA (80, 155, and $240 \mu \mathrm{g} \cdot \mathrm{ml}^{-1}$ ) was observed negligible and recorded as $1.1,2.2$, and $2.8 \%$, respectively. Furthermore, we employed Cyt C release assay to substantiate our apoptotic results. With reference to control cells, the relative percentage of Cyt $\mathrm{C}$ release from mitochondria to cytosol in the presence of ML-CNMA (240 mg. $\left.\mathrm{l}^{-1}\right)$ was increased from 63 to $139 \%$, respectively (Figure 5B). The upshot of the increased concentration of Cyt $\mathrm{C}$ in the cytoplasm eventually leads to the apoptosis, which corroborates with our TEM and SEM results (Figure 4).

\section{Interaction of CNMA with 14- $\alpha$ Demethylase of C. albicans}

To further understand a putative mode of action of CNMA, molecular modeling and docking study was performed. Earlier, 

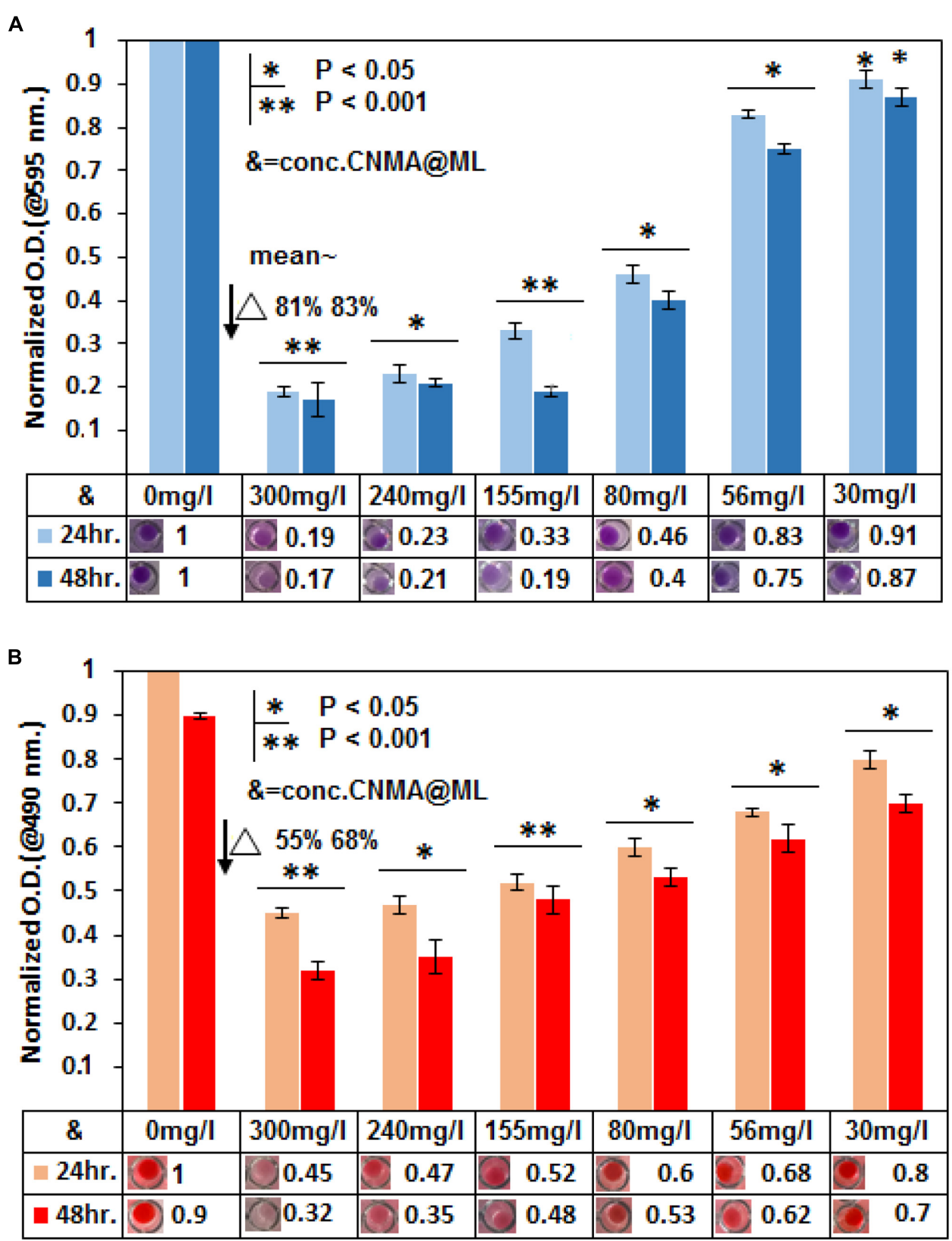

FIGURE 3 | Reduction in biofilm formation was assessed by crystal violet assay and XTT. In crystal violet assay (A) as well as in XTT (B), six different concentrations $\left(300,240,155,80,56\right.$, and $\left.30 \mathrm{mg} \cdot \mathrm{I}^{-1}\right)$ of CNMA (@/in ML) were used to treat the Candida biofilm and results were normalized with an untreated sample. Control (untreated) and treated biofilm were grown for 24 and $48 \mathrm{~h}$. The final values were mean optical density (OD) at 595 and $490 \mathrm{~nm}$, respectively. Error bars indicate the standard error of the mean of three independent experiments performed in triplicates. Asterisks represent the significant difference in percentage biofilm reduction as compared with control, ${ }^{*} P<0.05,{ }^{* *} P<0.001$.

various molecular mechanism showed the C. albicans strains' resistance against Azoles antifungal agents. The target enzyme of azoles is 14-demethylase (Erg11p), a strategic enzyme in the ergosterol synthesis pathway and block the fungal membrane formation. The overexpression of Erg11p also contributes the fungal resistance (Ramage et al., 2012). CNMA was docked to modeled 14- $\alpha$ demethylase of $C$. albicans (Figure 5C), which illustrates the overlapping binding pocket of CNMA with azole drug such as Fluconazole (Supplementary Figure S7). Most of the amino acids involved in the binding interactions were found to be common when tested with CNMA and fluconazole binding with 14- $\alpha$ demethylase (Figure 5E). These results were suggestive of the similar mechanistic outcome of CNMA with 14- $\alpha$ demethylase as in the case of azole drugs due to its similar interactions with the targets (Figures 5D,E). 

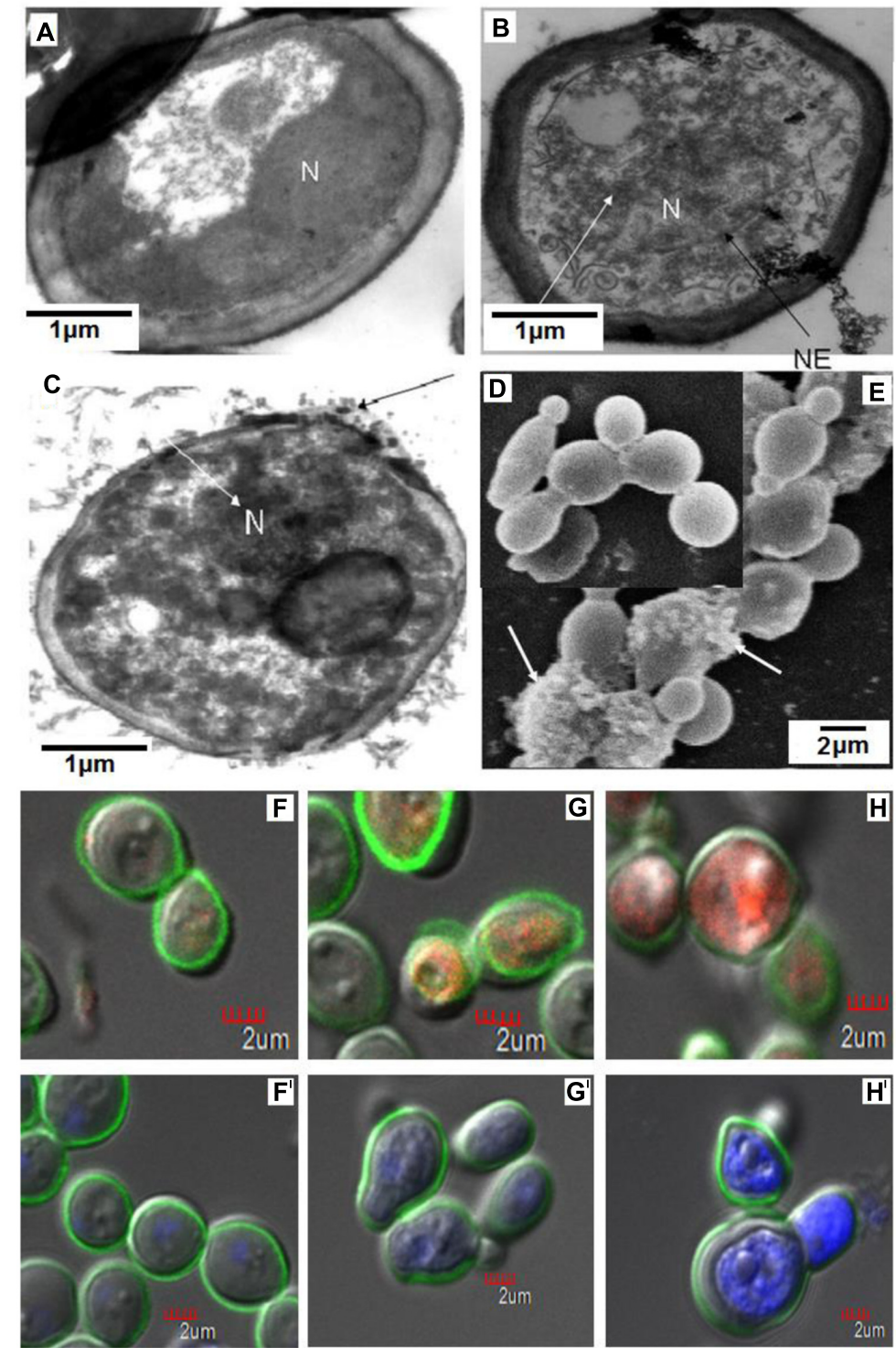

I<smiles>CC(=O)OC1=CC2Oc3cc(OC(C)=O)c(Cl)cc3C(c3ccccc3C(=O)O)C2C=C1Cl</smiles>

Cellular

Cellular Esterase penetration

cytoplasmic ROS<smiles>O=C1OC2(c3cc(Cl)c(O)cc3OC3C=C(O)C(Cl)=CC32)c2ccccc21</smiles>

J fluorescent DCF
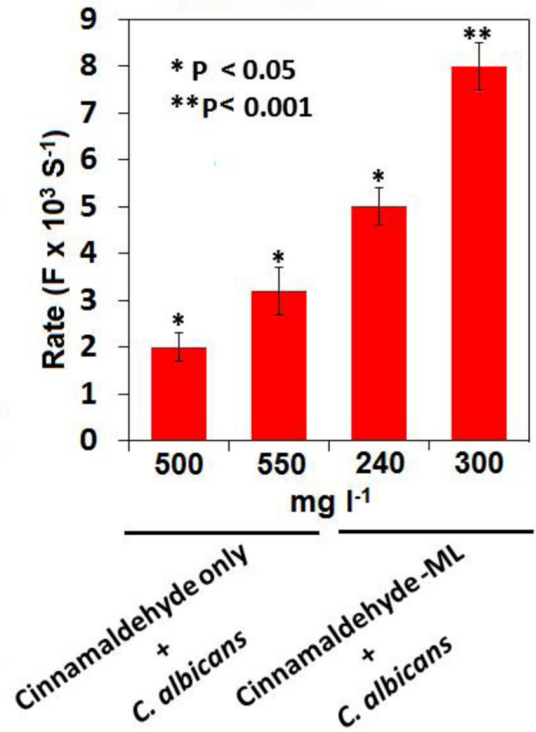

FIGURE 4 | Probing cytometabolic outcomes of ML-CNMA treatment on Candida cells. Electron transmission micrographs of Candida cells grown for 12 h shows normal Candida cells (without any treatment) (A), and intermediate stages (B,C) after treatment with $\mathrm{ML}-\mathrm{CNMA}\left(240\right.$ and 300 mg.| $\left.\left.\right|^{-1}\right)$, which eventually leads to apoptotic programmed cell death. Panel (B) shows chromatin condensation (white arrow) and nuclear envelope (NE) in the black arrow. Panel (C) shows the tiny vesicles on the outer face of the plasma membrane (black arrow) as well as chromatin condensation (white arrow). $\mathrm{N}$ is the nucleus. Panel (E) shows SEM of an apoptotic Candida cell treated for $36 \mathrm{~h}$ with ML-CNMA (300 mg. $\left.\right|^{-1}$ ), where surface blebbing is evident (white arrow) a sign of apoptosis in comparison to untreated cells (D). The panels (F-H) stained with FUN1 and ConA, whereas $\left(\mathbf{F}^{\prime}-\mathbf{H}^{\prime}\right)$ stained with DAPI and ConA. Though panels $\left(\mathbf{F}, \mathbf{F}^{\prime}\right)$ depict untreated cells but panels $\left(\mathbf{G}, \mathbf{G}^{\prime}, \mathbf{H}, \mathbf{H}^{\prime}\right)$ represent treated cells (80 and $\left.240 \mathrm{mg} \cdot \cdot^{-1}\right)$. (I,J) Quantification of (ROS-induced) cytoplasmic DCF green fluor generation. The enhancement of fluorescence rate $\left(F \times 10^{-3} \cdot S^{-1}\right)$; corresponding to ROS production after the treatment of CNMA in presence and absence of ML. Error bars indicate the standard error of the mean of three independent experiments performed in triplicates. Asterisks represent the significant difference in florescence rate compared with control, $* P<0.05, * * P<0.001$.

\section{Effect of ML-CNMA on HWP1 Gene Expression}

In another approach to assessing the effect of ML-CNMA on biofilm formation, HWP1 gene expression was analyzed. The biofilm formation was initiated by hyphae formation that is imperative to adherence on biotic as well as abiotic surface. The hyphal wall protein (Hwpl) initiates the adherence and biofilm formation. Moreover, inhibition of biofilm formation is directly correlated with HWP1 expression (Nobile et al., 2006). HWP1 expression was probed when cells were incubated with ML-CNMA (Figure 6A), showing the filamentous cells during normal biofilm formation (Hogan et al., 2004). RNA was isolated from cells incubated in the presence ( 80 and $300 \mathrm{mg} \cdot \mathrm{l}^{-1}$ ) and absence of ML-CNMA. Reduction in HWP1 expression was 


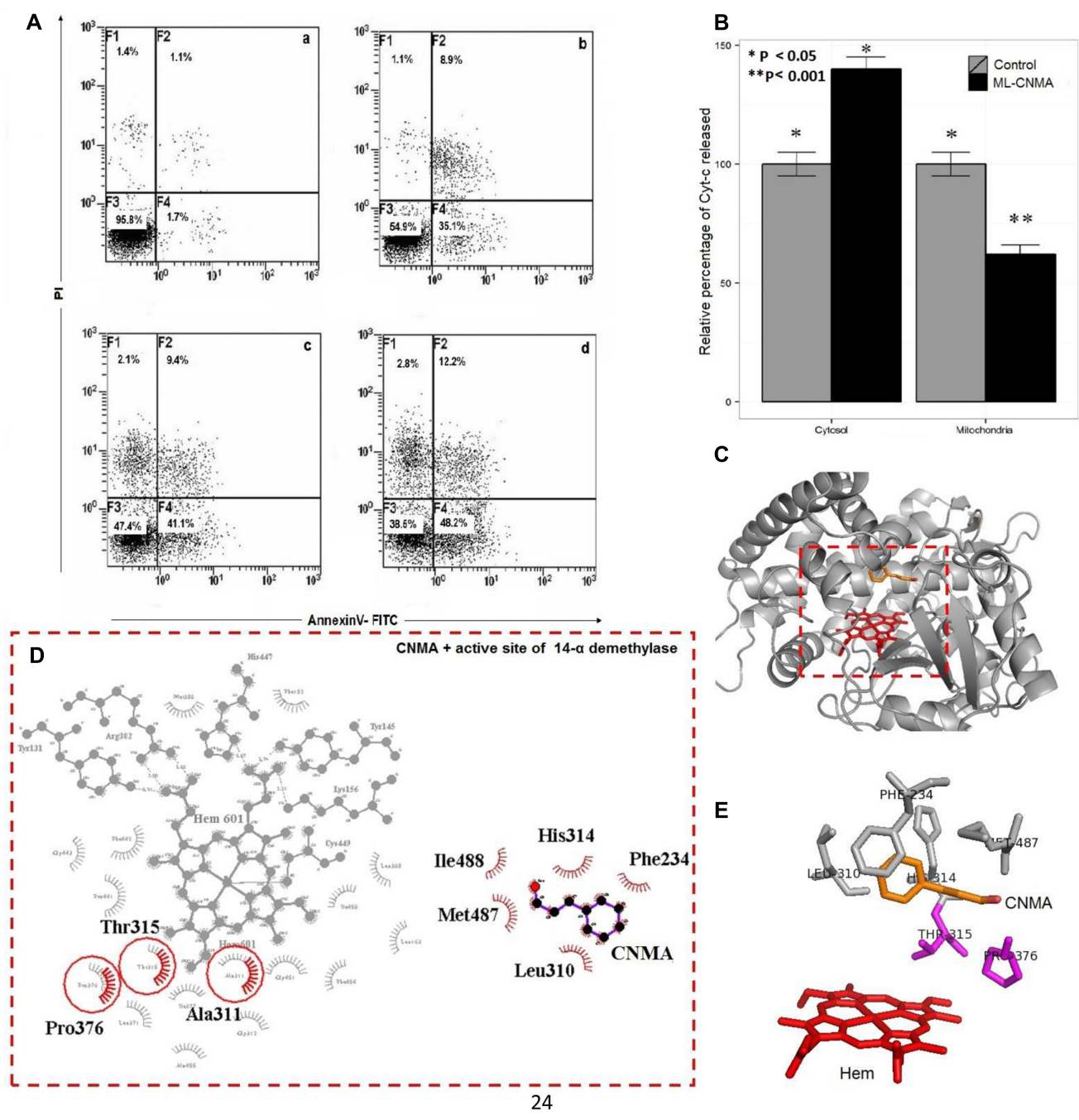

FIGURE 5 | (A) Candida albicans was treated with ML-CNMA for 2 h: panel (a) is control (without any treatment) whereas panels (b-d) were treated with 80, 155, and $240 \mu \mathrm{g} / \mathrm{ml}$ of ML-CNMA. The figure shown was from a representative experiment repeated three times with almost similar results. (B) The effect of ML-CNMA on Cyt $\mathrm{C}$ release from mitochondria to cytosol in $\mathrm{C}$. albicans. Concentrations of ascorbic acid-reduced Cyt $\mathrm{C}$ in mitochondria and cytosol were determined by

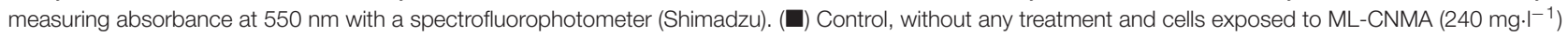
were observed. (C,D) The Molecular modeling representation of 14- $\alpha$ demethylase active site and its binding interactions with CNMA. (E) The most common amino acids involved in the hydrophobic interactions (Thr315, Pro376, Met487, Leu310, His314, and Phe234) with Azole drug (such as Fluconazole) are also involved in with CNMA. Error bars indicate the standard error of the mean of three independent experiment performed in triplicate was considered significance, ${ }^{*} P<0.05$, ${ }^{* *} P<0.001$

observed when Candida cells were incubated with the increasing concentration of ML-CNMA/CNMA alone (Figure 6C). Our data suggests that the gene involved in true hyphal formation was downregulated on treatment with ML-CNMA and leads to decrease in adherence and biofilm initiation (Figure 6D). Herein, $E F B 1$ gene of C. albicans was used as a control for uniform expression (housekeeping effect).

\section{DISCUSSION}

To date, several antifungal (Leal et al., 2015) and antibacterial (Gubernator et al., 2007) drugs have been given as encapsulated liposomal formulations to enhance their therapeutic index. In particular, Amp B has been studied exclusively with the aim to reduce its toxicity and side-effects by entrapping into lipid complex and multilamellar (ML) vesicles (Tang et al., 2015). The outermost bilayer of multilamellar phospholipid vesicles fuses with the plasma membrane of the cell, providing increased surface area and invagination of the excess plasma membrane (Batzri and Korn, 1975). In agreement with this, our ML-CNMA results showed more sensitivity than free CNMA are further confirmed by spot test assay (Figure 1), which possibly be the result of the sustained release of CNMA in encapsulated form. Earlier it has been reported that fungicidal potential was slightly higher for the multilamellar vesicles than for the 
A
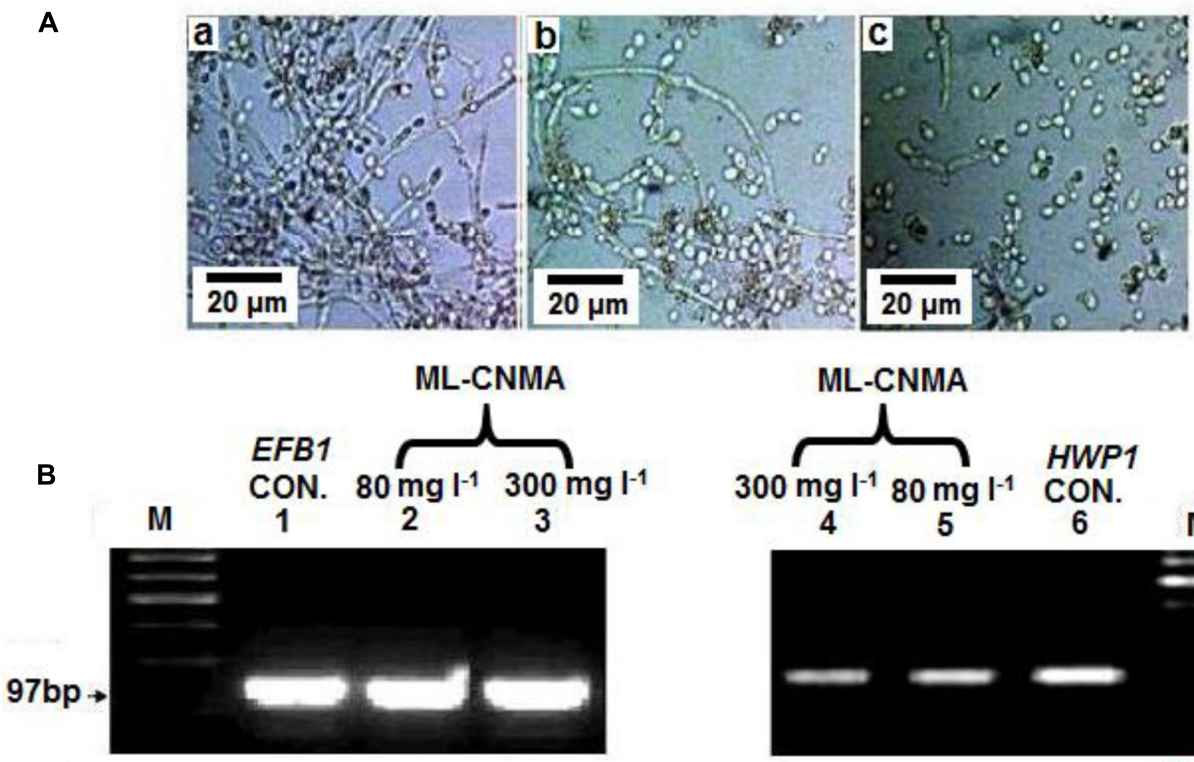


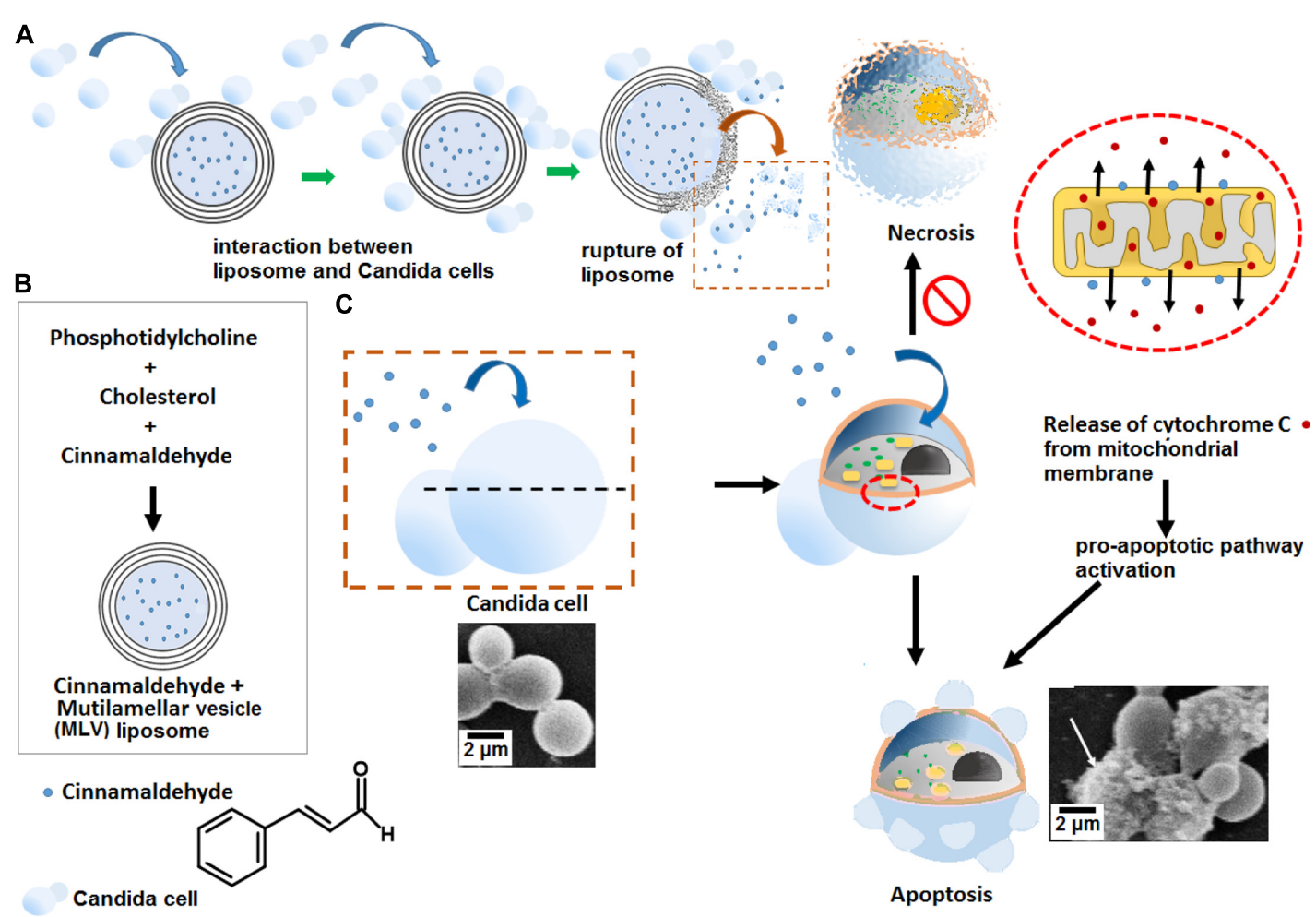

FIGURE 7 | Illustrative schematic mechanism of ML-CNMA-induced apoptosis in C. albicans. (A) ML liposome interacts with C. albicans and leads to rupture of ML-CNMA and finally releases of CNMA. (B) This liposome has trapped CNMA and (C) after the rupture of liposomes, CNMA induced the elevation of mitochondrial potential, causing ROS accumulation in mitochondria, and resulting in the release of Cyt C to the cytosol. Both ROS and Cyt C activated the pro-apoptotic pathway, which may trigger apoptosis in C. albicans.

The results of TEM illustrates ML-CNMA induced condensation of chromatin (Figures 4B,C), an established marker of yeast apoptosis, indicating the DNA damage caused by ML-CNMA action in C. albicans. Moreover, treatment showed a remarkable effect on the cellular surface, with extensive roughening and/or blebbing (Figure 4D), further its treatment results in cytological perturbation (Figures $4 \mathrm{~F}-\mathrm{H}$ ). FUN-1, Con-A, and DAPI fluorescent probes in CLSM micrographs illustrate the decrease of metabolic viability, loss of cell wall integration, and fragmentation or degradation of nuclear DNA (Khan et al., 2012). As ML-CNMA treatment evokes ROS potential in Candida cell (Figure 4J), which suggests ROS driven cellular injury.

Furthermore, ML-CNMA showed better antibiofilm activity (Figures 2C, 3) and negligible necrosis as shown in our FACS analysis (Figure 5A) suggesting its use with lesser unspecific toxicity. As here, we observed only early apoptosis and a negligible amount of late apoptosis in the presence of ML-CNMA, whereas free CNMA showed approximately same early and late apoptosis (data not shown), which further corroborates with our spot test results (Figure 1). Moreover, to elucidate the possible role of ML-CNMA, Cyt C release assay was further performed (Figure 5B). The results illustrate ML-CNMA induced mitochondrial hyperpolarization in C. albicans ( $\mathrm{Wu}$ et al., 2009) and possible induction of apoptotic pathway (Desagher and Martinou, 2000). This increase in Cyt C concentration in cytosol evokes ROS generation, which is also a proapoptotic event (De Logu et al., 1997). Hence, this implicates that the ML-CNMA extract may induce apoptosis through the metacaspase-dependent apoptotic pathway, which is activated by Cyt $\mathrm{C}$ release and ROS production, as depicted in the suggestive scheme (Figure 7).

When probed for gene expression, results illustrates repression of the gene implicated in biofilm formation and true hyphal formation on ML-CNMA treatment and thereby inhibits the process of biofilm formation, which further corroborates with our SEM results in Figure 2. Earlier studies were also in accordance with our findings by suggesting a correlation between HWP1 expression and biofilm formation (Nobile et al., 2006). Molecular modeling and docking studies revealed molecular interaction involved of CNMA with 14- $\alpha$ demethylase of Candida (Figure 7). The inhibition of fungal cell wall synthesizing enzymes by transCNMA has also been studied earlier (Bang et al., 2000). Which is a cell wall active antifungal agent that acts as a potentiator by reducing the cell wall synthesis and facilitating the leakage of fungal cytoplasm (Yen and Chang, 2008). Furthermore, our results (Figures 5C-E) suggest the binding of CNMA at the active site of the enzyme and amino acid residues involved in the interactions of CNMA are overlapping to azole binding drugs 
(Baginski and Czub, 2009). Hence, a similar interaction of CNMA as of azole drugs is suggested upon its treatment (Paranagama et al., 2010).

Evidence regarding mitochondrial involvement in the induction of yeast apoptosis in response to different stimuli has been well established (Ludovico et al., 2002). Our FACS analysis (Figure 6A) release of Cyt C (Figure 6B) data and TEM data (Figure 4) showed the apoptotic effect in the presence of ML-CNMA and is strongly supported by the crucial role of mitochondria in cell death induced by hyperosmotic stress (Silva et al., 2005). This study concludes the potential use of ML-CNMA as an antifungal and antibiofilm agent. The findings of this study demonstrate that ML-CNMA retards the proliferation of $C$. albicans and promotes apoptosis. This is the first study, using ML-CNMA extract to induce apoptosis in C. albicans and hence suggesting its potential use against Candida infections in immune compromised patients. Moreover, this study also recommends the multilamellar liposomal preparation of antifungal compounds to increase the efficacy of antifungal agents.

\section{REFERENCES}

Baginski, M., and Czub, J. (2009). Amphotericin B and its new derivatives-mode of action. Curr. Drug Metab. 10, 459-469. doi: 10.2174/138920009788898019

Bandara, H., Yau, J., Watt, R., Jin, L., and Samaranayake, L. (2010). Pseudomonas aeruginosa inhibits in-vitro Candida biofilm development. BMC Microbiol. 10:125. doi: 10.1186/1471-2180-10-125

Bang, K.-H., Lee, D.-W., Park, H.-M., and Rhee, Y.-H. (2000). Inhibition of fungal cell wall synthesizing enzymes by trans-cinnamaldehyde. Biosci. Biotechnol. Biochem. 64, 1061-1063. doi: 10.1271/bbb.64.1061

Batzri, S., and Korn, E. D. (1975). Interaction of phospholipid vesicles with cells. Endocytosis and fusion as alternate mechanisms for the uptake of lipid-soluble and water-soluble molecules. J Cell Biol. 66, 621-634. doi: 10.1083/jcb.66. 3.621

Berenguer, J., Munoz, P., Parras, F., Fernandez-Baca, V., Hernandez-Sampelayo, T., and Bouza, E. (1994). Treatment of deep mycoses with liposomal amphotericin B. Eur. J. Clin. Microbiol. Infect. Dis. 13, 504-507. doi: 10.1007/BF01974643

Bozzola, J. J., and Russell, L. D. (1999). Electron Microscopy: Principles and Techniques for Biologists. Burlington, MA: Jones \& Bartlett Learning.

Bradford, M. M. (1976). A rapid and sensitive method for the quantitation of microgram quantities of protein utilizing the principle of protein-dye binding. Anal. Biochem. 72, 248-254. doi: 10.1016/0003-2697(76)90527-3

Caillot, D., Casasnovas, O., Solary, E., Chavanet, P., Bonnotte, B., Reny, G., et al. (1993). Efficacy and tolerance of an amphotericm B lipid (Intralipid) emulsion in the treatment of candidaemia in neutropenic patients. J. Antimicrob. Chemother. 31, 161-169. doi: 10.1093/jac/31.1.161

Chandra, J., Kuhn, D. M., Mukherjee, P. K., Hoyer, L. L., Mccormick, T., and Ghannoum, M. A. (2001). Biofilm formation by the fungal pathogen Candida albicans: development, architecture, and drug resistance. J. Bacteriol. 183, 5385-5394. doi: 10.1128/JB.183.18.5385-5394.2001

Chandra, J., Mukherjee, P. K., and Ghannoum, M. A. (2008). In vitro growth and analysis of Candida biofilms. Nat. Protoc. 3:1909. doi: 10.1038/nprot.2008.192

Clinical and Laboratory Standards Institute (2008). Reference Method for Broth Dilution Antifungal Susceptibility Testing of Yeasts. Approved Standard. Document M27-A3. Wayne, PA: Clinical and Laboratory Standards Institute.

Costerton, J. W., Stewart, P. S., and Greenberg, E. P. (1999). Bacterial biofilms: a common cause of persistent infections. Science 284, 1318-1322. doi: 10.1126/ science. 284.5418 .1318

Daghastanli, N. A., Itri, R., and Baptista, M. S. (2008). Singlet oxygen reacts with $2^{\prime}, 7^{\prime}$-dichlorodihydrofluorescein and contributes to the formation of $2^{\prime}, 7^{\prime}$ dichlorofluorescein. Photochem. Photobiol. 84, 1238-1243. doi: 10.1111/j.17511097.2008.00345.x

\section{AUTHOR CONTRIBUTIONS}

AK, SK, and SNK designed the experiments. SK, SNK, JI, and RK performed the experiments. AK, SNK, and SK wrote the paper. $\mathrm{AK}$ and SNK reviewed the manuscript. All authors reviewed the paper.

\section{FUNDING}

This work was supported by internal funds of Biotechnology Unit, AMU to AK. DST sanction no ECR/2015/000048 to SNK. SK thank CSIR-SRF for a fellowship.

\section{SUPPLEMENTARY MATERIAL}

The Supplementary Material for this article can be found online at: http://journal.frontiersin.org/article/10.3389/fmicb. 2017.01641/full\#supplementary-material

Davis-Hanna, A., Piispanen, A. E., Stateva, L. I., and Hogan, D. A. (2008). Farnesol and dodecanol effects on the Candida albicans Ras1-cAMP signalling pathway and the regulation of morphogenesis. Mol. Microbiol. 67, 47-62. doi: 10.1111/j. 1365-2958.2007.06013.x

De Logu, A., Fadda, A., Anchisi, C., Maccioni, A., Sinico, C., Schivo, M., et al. (1997). Effects of in-vitro activity of miconazole and ketoconazole in phospholipid formulations. J. Antimicrob. Chemother. 40, 889-893. doi: $10.1093 / \mathrm{jac} / 40.6 .889$

Desagher, S., and Martinou, J.-C. (2000). Mitochondria as the central control point of apoptosis. Trends Cell Biology 10, 369-377. doi: 10.1016/S0962-8924(00) 01803-1

Dong, J., Signo, K. S., Vanderlinde, E. M., Yost, C. K., and Dahms, T. E. (2011). Atomic force microscopy of a ctpA mutant in Rhizobium leguminosarum reveals surface defects linking CtpA function to biofilm formation. Microbiology 157, 3049-3058. doi: 10.1099/mic.0.051045-0

Donlan, R. M. (2001). Biofilm formation: a clinically relevant microbiological process. Clin. Infect. Dis. 33, 1387-1392. doi: 10.1086/322972

Fidel, P. (2006). Candida-host interactions in HIV disease: relationships in oropharyngeal candidiasis. Adv. Dent. Res. 19, 80-84. doi: 10.1177/ 154407370601900116

Gubernator, J., Drulis-Kawa, Z., Dorotkiewicz-Jach, A., Doroszkiewicz, W., and Kozubek, A. (2007). In vitro antimicrobial activity of liposomes containing ciprofloxacin, meropenem and gentamicin against gram-negative clinical bacterial strains. Lett. Drug Design Discov. 4, 297-304. doi: 10.2174/ 157018007784620040

Harrington, B. J., and Williams, D. L. (2007). Rapid, presumptive identification of Torulopsis (Candida) glabrata and Candida krusei using calcofluor white. Lab. Med. 38, 227-231. doi: 10.1309/853FEYVAAG5LHPXW

Hawser, S. P., and Douglas, L. J. (1995). Resistance of Candida albicans biofilms to antifungal agents in vitro. Antimicrob. Agents Chemother. 39, 2128-2131. doi: 10.1128/AAC.39.9.2128

Hogan, D. A., Vik, Å, and Kolter, R. (2004). A Pseudomonas aeruginosa quorumsensing molecule influences Candida albicans morphology. Mol. Microbiol. 54, 1212-1223. doi: 10.1111/j.1365-2958.2004.04349.x

Hopfer, R., Mills, K., Mehta, R., Lopez-Berestein, G., Fainstein, V., and Juliano, R. (1984). In vitro antifungal activities of amphotericin B and liposomeencapsulated amphotericin B. Antimicrob. Agents Chemother. 25, 387-389. doi: 10.1128/AAC.25.3.387

Jin, Y., Yip, H., Samaranayake, Y., Yau, J., and Samaranayake, L. (2003). Biofilmforming ability of Candida albicans is unlikely to contribute to high levels of oral yeast carriage in cases of human immunodeficiency virus infection. J. Clin. Microbiol. 41, 2961-2967. doi: 10.1128/JCM.41.7.2961-2967.2003 
Jin, Y., Zhang, T., Samaranayake, Y., Fang, H., Yip, H., and Samaranayake, L. (2005). The use of new probes and stains for improved assessment of cell viability and extracellular polymeric substances in Candida albicans biofilms. Mycopathologia 159, 353-360. doi: 10.1007/s11046-004-6987-7

Kang, L.-L., Zhang, D.-M., Ma, C.-H., Zhang, J.-H., Jia, K.-K., Liu, J.-H., et al. (2016). Cinnamaldehyde and allopurinol reduce fructose-induced cardiac inflammation and fibrosis by attenuating CD36-mediated TLR4/6-IRAK4/1 signaling to suppress NLRP3 inflammasome activation. Sci. Rep. 6:27460. doi: $10.1038 /$ srep27460

Khan, S., Alam, F., Azam, A., and Khan, A. U. (2012). Gold nanoparticles enhance methylene blue-induced photodynamic therapy: a novel therapeutic approach to inhibit Candida albicans biofilm. Int. J. Nanomed. 7:3245. doi: 10.2147/IJN. S31219

Khan, S. N., Islam, B., Yennamalli, R., Zia, Q., Subbarao, N., and Khan, A. U. (2008). Characterization of doxorubicin binding site and drug induced alteration in the functionally important structural state of oxyhemoglobin. J. Pharm. Biomed. Anal. 48, 1096-1104. doi: 10.1016/j.jpba.2008.08.030

Khan, S. N., and Khan, A. U. (2016). Breaking the spell: combating multidrug resistant 'superbugs'. Front. Microbiol. 7:174. doi: 10.3389/fmicb.2016.00174

Kuhn, D., Balkis, M., Chandra, J., Mukherjee, P., and Ghannoum, M. (2003). Uses and limitations of the XTT assay in studies of Candida growth and metabolism. J. Clin. Microbiol. 41, 506-508. doi: 10.1128/JCM.41.1.506-508.2003

Kuhn, D., Chandra, J., Mukherjee, P., and Ghannoum, M. (2002). Comparison of biofilms formed by Candida albicans and Candida parapsilosis on bioprosthetic surfaces. Infect. Immun. 70, 878-888. doi: 10.1128/IAI.70.2.878-888.2002

Larsen, R. A., Bauer, M., Thomas, A. M., Sanchez, A., Citron, D., Rathbun, M., et al. (2005). Correspondence of in vitro and in vivo fluconazole dose-response curves for Cryptococcus neoformans. Antimicrob. Agents Chemother. 49, 3297-3301. doi: 10.1128/AAC.49.8.3297-3301.2005

Leal, A. F. G., Leite, M. C., Medeiros, C. S. Q., Cavalcanti, I. M. F., Wanderley, A. G., Magalhaes, N. S. S., et al. (2015). Antifungal activity of a liposomal itraconazole formulation in experimental Aspergillus flavus keratitis with endophthalmitis. Mycopathologia 179, 225-229. doi: 10.1007/s11046-014-9837-2

Lin, L.-T., Tai, C.-J., Chang, S.-P., Chen, J.-L., Wu, S.-J., and Lin, C.-C. (2013). Cinnamaldehyde-induced apoptosis in human hepatoma PLC/PRF/5 cells involves the mitochondrial death pathway and is sensitive to inhibition by cyclosporin A and z-VAD-fmk. Anticancer Agents Med. Chem. 13, 1565-1574. doi: 10.2174/18715206113139990144

Ludovico, P., Rodrigues, F., Almeida, A., Silva, M. T., Barrientos, A., and CôrteReal, M. (2002). Cytochrome c release and mitochondria involvement in programmed cell death induced by acetic acid in Saccharomyces cerevisiae. Mol. Biol. Cell 13, 2598-2606. doi: 10.1091/mbc.E01-12-0161

Madeo, F., Fröhlich, E., and Fröhlich, K.-U. (1997). A yeast mutant showing diagnostic markers of early and late apoptosis. J. Cell Biol. 139, 729-734. doi: $10.1083 /$ jcb.139.3.729

Madeo, F., Fröhlich, E., Ligr, M., Grey, M., Sigrist, S. J., Wolf, D. H., et al. (1999). Oxygen stress: a regulator of apoptosis in yeast. J. Cell Biol. 145, 757-767. doi: $10.1083 /$ jcb.145.4.757

Mah, T.-F. C., and O’Toole, G. A. (2001). Mechanisms of biofilm resistance to antimicrobial agents. Trends Microbiol. 9, 34-39. doi: 10.1016/S0966-842X(00) 01913-2

Michelet, C., Arvieux, C., François, C., Besnier, J. M., Rogez, J. P., Breux, J. P., et al. (1998). Opportunistic infections occurring during highly active antiretroviral treatment. Aids 12, 1815-1822. doi: 10.1097/00002030-19981400000013

Molania, T., Moghadamnia, A. A., Pouramir, M., Aghel, S., Moslemi, D., Ghassemi, L., et al. (2012). The effect of Cinnamaldehyde on mucositis and salivary antioxidant capacity in gamma-irradiated rats (a preliminary study). Daru 20:89. doi: 10.1186/2008-2231-20-89

Morgan, J. (2005). Global trends in candidemia: review of reports from 1995-2005. Curr. Infect. Dis. Rep. 7, 429-439. doi: 10.1007/s11908-005-0044-7

Nobile, C. J., Nett, J. E., Andes, D. R., and Mitchell, A. P. (2006). Function of Candida albicans adhesin Hwp1 in biofilm formation. Eukaryot. Cell 5, 1604-1610. doi: 10.1128/EC.00194-06

Paranagama, P., Wimalasena, S., Jayatilake, G., Jayawardena, A., Senanayake, U., and Mubarak, A. (2010). A comparison of essential oil constituents of bark, leaf, root and fruit of cinnamon (Cinnamomum zeylanicum Blum) grown in
Sri Lanka. J. Natn. Sci. Found. Sri Lanka 29, 147-153. doi: 10.4038/jnsfsr.v29i34.2613

Park, B. J., Arthington-Skaggs, B. A., Hajjeh, R. A., Iqbal, N., Ciblak, M. A., LeeYang, W., et al. (2006). Evaluation of amphotericin B interpretive breakpoints for Candida bloodstream isolates by correlation with therapeutic outcome. Antimicrob. Agents Chemother. 50, 1287-1292. doi: 10.1128/AAC.50.4.12871292.2006

Perlroth, J., Choi, B., and Spellberg, B. (2007). Nosocomial fungal infections: epidemiology, diagnosis, and treatment. Med. Mycol. 45, 321-346. doi: 10.1080/ 13693780701218689

Pfaller, M. A. (1996). Nosocomial candidiasis: emerging species, reservoirs, and modes of transmission. Clin. Infect. Dis. 22, S89-S94. doi: 10.1093/clinids/22. Supplement_2.S89

Phillips, A. J., Sudbery, I., and Ramsdale, M. (2003). Apoptosis induced by environmental stresses and amphotericin B in Candida albicans. Proc. Natl. Acad. Sci. U.S.A. 100, 14327-14332. doi: 10.1073/pnas.2332326100

R Development Core Team (2013). R: A Language and Environment for Statistical Computing. Vienna: R Foundation for Statistical Computing.

Ralph, E., Khazindar, A., Barber, K., and Grant, C. (1991). Comparative in vitro effects of liposomal amphotericin B, amphotericin B-deoxycholate, and free amphotericin B against fungal strains determined by using MIC and minimal lethal concentration susceptibility studies and timekill curves. Antimicrob. Agents Chemother. 35, 188-191. doi: 10.1128/AAC. 35.1.188

Ramage, G., Rajendran, R., Sherry, L., and Williams, C. (2012). Fungal biofilm resistance. Int. J. Microbiol. 2012:528521. doi: 10.1155/2012/528521

Ramage, G., Saville, S. P., Thomas, D. P., and Lopez-Ribot, J. L. (2005). Candida biofilms: an update. Eukaryot. Cell 4, 633-638. doi: 10.1128/EC.4.4.633-638. 2005

Revankar, S., Sanche, S., Dib, O., Caceres, M., and Patterson, T. (1998). Effect of highly active antiretroviral therapy on recurrent oropharyngeal candidiasis in HIV-infected patients. AIDS 12, 2511-2513.

Ritz, C., Baty, F., Streibig, J. C., and Gerhard, D. (2015). Dose-response analysis using R. PLoS ONE 10:e0146021. doi: 10.1371/journal.pone.0146021

Shirtliff, M. E., Krom, B. P., Meijering, R. A., Peters, B. M., Zhu, J., Scheper, M. A., et al. (2009). Farnesol-induced apoptosis in Candida albicans. Antimicrob. Agents Chemother. 53, 2392-2401. doi: 10.1128/AAC.01551-08

Shreaz, S., Wani, W. A., Behbehani, J. M., Raja, V., Irshad, M., Karched, M., et al. (2016). Cinnamaldehyde and its derivatives, a novel class of antifungal agents. Fitoterapia 112, 116-131. doi: 10.1016/j.fitote.2016.05.016

Silva, R. D., Sotoca, R., Johansson, B., Ludovico, P., Sansonetty, F., Silva, M. T., et al. (2005). Hyperosmotic stress induces metacaspase-and mitochondriadependent apoptosis in Saccharomyces cerevisiae. Mol. Microbiol. 58, 824-834. doi: 10.1111/j.1365-2958.2005.04868.x

Soh, N. (2006). Recent advances in fluorescent probes for the detection of reactive oxygen species. Anal. Bioanal. Chem. 386, 532-543. doi: 10.1007/s00216-0060366-9

Streibig, J. C., Rudemo, M., and Jensen, J. E. (1993). "Dose-response curves and statistical models," in Herbicide Bioassays, eds J. C. Streibig and P. Kudsk (Boca Raton, FL: CRC Press), 29-55.

Tang, X., Liang, Y., Zhu, Y., Xie, C., Yao, A., Chen, L., et al. (2015). Anti-transferrin receptor-modified amphotericin B-loaded $\mathrm{Pla}-\mathrm{Peg}$ nanoparticles cure candidal meningitis and reduce drug toxicity. Int. J. Nanomed. 10:6227. doi: 10.2147/IJN. S84656

Trafny, E. A., Stepiñska, M., Antos, M., and Grzybowski, J. (1995). Effects of free and liposome-encapsulated antibiotics on adherence of Pseudomonas aeruginosa to collagen type I. Antimicrob. Agents Chemother. 39, 2645-2649. doi: 10.1128/AAC.39.12.2645

Venkatachalam, C. M., Jiang, X., Oldfield, T., and Waldman, M. (2003). LigandFit: a novel method for the shape-directed rapid docking of ligands to protein active sites. J. Mol. Graph. Model. 21, 289-307. doi: 10.1016/S1093-3263(02)00164-X

Wadhwa, A., Kaur, R., Agarwal, S. K., Jain, S., and Bhalla, P. (2007). AIDS-related opportunistic mycoses seen in a tertiary care hospital in North India. J. Med. Microbiol. 56, 1101-1106. doi: 10.1099/jmm.0.46893-0

Wei, Q.-Y., Xiong, J.-J., Jiang, H., Zhang, C., and Ye, W. (2011). The antimicrobial activities of the cinnamaldehyde adducts with amino acids. Int. J. Food Microbiol. 150, 164-170. doi: 10.1016/j.ijfoodmicro.2011.07.034 
Westwater, C., Balish, E., and Schofield, D. A. (2005). Candida albicansconditioned medium protects yeast cells from oxidative stress: a possible link between quorum sensing and oxidative stress resistance. Eukaryot. Cell 4, 1654-1661. doi: 10.1128/EC.4.10.1654-1661.2005

Wu, X.-Z., Chang, W.-Q., Cheng, A.-X., Sun, L.-M., and Lou, H.-X. (2010). Plagiochin E, an antifungal active macrocyclic bis (bibenzyl), induced apoptosis in Candida albicans through a metacaspase-dependent apoptotic pathway. Biochim. Biophys. Acta 1800, 439-447. doi: 10.1016/j.bbagen.2010.01.001

Wu, X.-Z., Cheng, A.-X., Sun, L.-M., Sun, S.-J., and Lou, H.-X. (2009). Plagiochin E, an antifungal bis (bibenzyl), exerts its antifungal activity through mitochondrial dysfunction-induced reactive oxygen species accumulation in Candida albicans. Biochim. Biophys. Acta 1790, 770-777. doi: 10.1016/j.bbagen.2009.05.002

Yen, T.-B., and Chang, S.-T. (2008). Synergistic effects of cinnamaldehyde in combination with eugenol against wood decay fungi. Bioresour. Technol. 99, 232-236. doi: 10.1016/j.biortech.2006.11.022
Zhang, B., Zhang, Y., Dagher, M.-C., and Shacter, E. (2005). Rho GDP dissociation inhibitor protects cancer cells against drug-induced apoptosis. Cancer Res. 65, 6054-6062. doi: 10.1158/0008-5472.CAN-050175

Conflict of Interest Statement: The authors declare that the research was conducted in the absence of any commercial or financial relationships that could be construed as a potential conflict of interest.

Copyright (c) 2017 Khan, Khan, Iqbal, Khan and Khan. This is an open-access article distributed under the terms of the Creative Commons Attribution License (CC BY). The use, distribution or reproduction in other forums is permitted, provided the original author(s) or licensor are credited and that the original publication in this journal is cited, in accordance with accepted academic practice. No use, distribution or reproduction is permitted which does not comply with these terms. 